\title{
Capsule Commentary on Peterson et al., Financial Exploitation of Older Adults: A Population Based Prevalence Study
}

\author{
Chris Strouse, MD and Jennifer Gomulka, BS
}

Medical College of Wisconsin, Milwaukee, WI, USA.

$\mathrm{J}$ Gen Intern Med 29(12): 1688

DOI: $10.1007 / \mathrm{s} 11606-014-2953-3$

(c) Society of General Internal Medicine 2014

$\mathrm{E}$ lder abuse increasingly has been recognized as an important and distressingly common issue faced by elderly patients. Acierno et al. ${ }^{1}$ found that $11.4 \%$ of elders reported at least one incident of abuse over the past year, including neglect, emotional, physical and sexual abuse. The present study by Peterson et al. ${ }^{2}$ highlights another form of abuse, financial abuse, and finds that it is likewise far too common.

The investigators determined the prevalence of financial exploitation of older adults (FEOA) by conducting 4,156 random number phone interviews in New York State. The 1year prevalence of FEOA was found to be $2.7 \%$, and the lifetime prevalence was $4.7 \%$. The true prevalence is likely even higher than what was reported given that the study was limited to competent adults (mental incapacity being a previously identified risk factor for financial abuse) and that it relied on self-reporting. In light of the established link between poverty and worse health outcomes, ${ }^{3}$ physicians would do well to identify victims of financial abuse.

To this end, Peterson et al. have identified a distinct set of risk factors for elders at high risk of financial exploitation: African-Americans, those living below the poverty line, those with disability and those with multiple non-spousal household members. It is among these patients that a particularly high index of suspicion should be maintained in order to identify and help victims of financial abuse. Harries et al. ${ }^{4}$ have reported on a free online training tool that has been shown to enhance a physician's ability to detect elder financial abuse. Financial institutions have also demonstrated an interest in identifying and limiting FEOA. For example, Wells Fargo has trained their employees to identify and respond to suspected FEOA. ${ }^{5}$ These efforts form a resource base for physicians to use in the clinic and identify possible partners in the financial industry that physicians may collaborate with in the future to combat FEOA. It is likely more resources will be necessary to adequately address this issue, and this report by Peterson et al. brings the need into focus.

Conflict of Interest: The authors have no conflict of interest with the material in this article.

Corresponding Author: Chris Strouse, MD; Medical College of Wisconsin, Milwaukee, WI 53226, USA (e-mail: cstrouse@mcw.edu).

\section{REFERENCES}

1. Acierno R, Hernandez M, Amstadter A, Resnick H, Steve K, Muzzy W, Kilpatrick D. Prevalence and correlates of emotional, physical, sexual, and financial abuse and potential neglect in the United States: The National Elder Mistreatment Study. American Journal of Public Health. 2010;100:292-7.

2. Peterson J, Burnes D, Caccamise P, Mason A, Henderson C, Wells M, Berman J, Cook A, Shukoff D, Brownell P, Powell M, Salamone A, Pillemer K, Lachs M. Financial exploitation of older adults: a population based prevalence study. J Gen Intern Med. 2014. doi:10.1007/s11606-0142946-2.

3. McCally M, Haines A, Fein O, Addington W, Lawrence RS, Cassel CK. Poverty and ill health: physicians can, and should, make a difference. Annals of Internal Medicine. 1998;129(9):726-33.

4. Harries P, Davies M, Gilhooly K, Gilhooly M, Tomlinson C. Educating novice practitioners to detect elder financial abuse: a randomised controlled trial. BMC medical education. 2014;14(1):21.

5. Forum on Global Violence Prevention; Board on Global Health; Institute of Medicine; National Research Council. Elder Abuse and Its Prevention: Workshop Summary. (National Academies Press (US), 2014) Chapter II.5, ELDER FINANCIAL ABUSE. PMID 24624478. 